\title{
Interdependent Followers Prefer Avoidant Leaders: Followers' Cultural Orientation Moderates Leaders' Avoidance Relationships with Followers' Work Outcomes
}

\section{OPEN ACCESS}

Edited by:

Pablo Fernández-Berrocal, University of Málaga, Spain

Reviewed by:

Anna Topakas,

University of Sheffield,

United Kingdom

Athena Xenikou,

Hellenic Air Force Academy,

Greece

*Correspondence: Konstantinos G. Kafetsios kafetsik@uoc.gr

Specialty section:

This article was submitted to Organizational Psychology, a section of the journal

Frontiers in Communication

Received: 01 November 2017 Accepted: 12 February 2018

Published: 01 March 2018

Citation:

Kafetsios KG and Gruda D (2018) Interdependent Followers Prefer Avoidant Leaders: Followers' Cultural

Orientation Moderates Leaders' Avoidance Relationships with Followers' Work Outcomes.

Front. Commun. 3:9.

doi: 10.3389/fcomm.2018.00009

\author{
Konstantinos G. Kafetsios ${ }^{1 *}$ and Dritjon Gruda ${ }^{2}$ \\ ${ }^{1}$ Psychology Department, University of Crete, Rethymno, Crete, Greece, ${ }^{2}$ School of Business, Maynooth University, \\ Maynooth, Ireland
}

Several studies examining leader-follower interaction in Greece, a collectivistic culture, paradoxically find that leaders' emotion suppression-related personality traits (attachment avoidance, emotion suppression, emotion control) are associated with followers' positive emotional and work attitude outcomes. These findings have been explained with reference to followers' implicit cultural schemas, interdependence in particular. Yet, this conjuncture has not been directly tested. The present study directly examined, in a field setting, how followers' independent and interdependent (cultural) self-construal moderate the relationship between leaders' attachment orientation and followers' emotion and satisfaction outcomes at the work place. As hypothesized, leaders' higher avoidance was associated with followers' job satisfaction, group cohesion, and deep acting as well as lower negative affect and loneliness for followers higher on interdependent self-construal. The results underline perceptual processes involved in followers' interdependent self-construal in relation to leaders' emotion suppression-related traits.

Keywords: leadership, adult attachment, cultural orientation, emotion regulation, work relationships

\section{INTRODUCTION}

In the last two decades, there has been a significant research interest in processes that can explain how leaders' emotion-related competencies impact followers' work outcomes. Numerous studies have demonstrated that emotion capabilities influence leaders' own and their followers' work experience in various ways (Ashkanasy et al., 2002), including followers' positive and negative emotion at work (Bono et al., 2007), team performance (Van Kleef et al., 2009), mood contagion (Bono and Ilies, 2006), and job satisfaction (Sŷ et al., 2006). Conceptually, there has been considerable convergence on the view that leaders' emotions and emotion-related competences impact followers' work-related attitudes and experience through direct, behavioral, and indirect, perceptive routes (Van Kleef et al., 2012). Followers' implicit personality theories can shape the perception of leaders' personality traits, including emotion-related competences and traits (Shondrick et al., 2010). The present research focuses on followers' cultural identity and how it can influence the perception of leaders' emotion-related competencies and hence followers' work outcomes. This is in chime with calls for research on leadership identity-related work in a multilevel fashion (Antonakis et al., 2012; Epitropaki et al., 2017).

Research questions for the present study were inspired on the basis of the following observation: a number of studies examining that leaders' emotion-related competencies have effects on their 
followers in Greece, a collectivistic culture (Hofstede, 2001), have returned a consistent finding: leaders' personality traits relating to higher emotion suppression have paradoxically positive relationships with followers' emotional and work attitude outcomes. Leaders' higher emotion suppression (Kafetsios et al., 2012), emotion control (Kafetsios et al., 2011), and avoidant attachment (Kafetsios et al., 2014) were associated with group of followers' higher positive affect and lower negative affect at work, higher job satisfaction, and a lower likelihood of burnout. This recursive finding is difficult to comprehend given extensive research that documents the negative consequences emotion suppression traits can have in interpersonal interactions (Butler et al., 2007; Tackman and Srivastava, 2016) including leader-follower interactions (Fisk and Friesen, 2012). One likely explanation is that followers' culturally informed leader perceptions moderate leaders' emotion-related traits effects on followers' work outcomes (see Kafetsios et al., 2014 for a related discussion). This hypothesis was directly investigated in this manuscript.

\section{Emotion Regulation in Leader-Follower Interaction}

Emotion regulation is a key emotion competency that characterizes an effective leadership style (Humphrey, 2002; Newcombe and Ashkanasy, 2002). Leaders manage and influence not only their own emotions and performance but also those of their subordinates (Pirola-Merlo et al., 2002) as well as conserve their subordinates' emotions (McColl-Kennedy and Anderson, 2002). However, relatively little is known as to whether and how leaders' emotion regulation strategies impact subordinates. Likewise, it is unclear whether those effects are consistent with popular arguments that describe most, if not all, leader emotion-related competencies as beneficial for leaders and followers alike, irrespective of organizational roles or contexts (e.g., Antonakis et al., 2009; Riggio and Lee, 2007; Sŷ et al., 2006).

Key theoretical frameworks such as the Emotions As Social Information model (EASI; Van Kleef et al., 2012) discuss mechanisms that link leaders' affect, emotions, and emotion displays with followers' attitudes and performance at the work place. Topical for the present study is the distinction between affectdriven (usually from leader to followers) and inference-driven (usually from followers to the leader) processes as applied to leader-follower interaction. We focus on followers' affective reactions in relation to followers' judgments or perceptions of leaders' certain emotion-related capabilities.

A number of field studies in Greece that directly examined relationships between leaders' facets of emotion regulation and followers' work outcomes have pointed to followers' perceptions of leaders' emotion-related competencies acting as mediators of followers' outcomes. An initial study of high-school directors and their subordinates found that leaders' higher regulation of emotion [measured with Wong and Law (2002)'s Emotional Intelligence Scale, an instrument of self-reported emotion-related competencies] was associated with followers' lower job satisfaction, and higher depersonalization, emotional exhaustion, and negative affect at work (Kafetsios et al., 2011). This finding was intriguing since leaders' emotion regulation skills were associated with leaders' own higher accomplishment and positive affect at work. A follow-up study (Kafetsios et al., 2012) specifically targeted leaders' emotion-related competencies, using Gross' emotion regulation scale (Gross and John, 2003). Similar to the previous study, leaders' emotion suppression was associated with followers' higher positive affect at work. Interestingly, leaders' reappraisal tendencies had negative consequences for followers' work-related outcomes, despite finding that reappraisal was associated with beneficial outcomes for leaders themselves (higher positive affect, group cohesion perceptions, and positive affect at work). Finally, a more recent two-sample study (Kafetsios et al., 2014) provided further support to our main thesis: Greek leaders' avoidant attachment orientation, an interpersonal schema associated with emotion suppression (Mikulincer and Shaver, 2007), was associated with followers' higher job satisfaction and affect at work. This is despite the fact that in both studies reported in Kafetsios et al. (2014) leaders' avoidance was linked with adverse work outcomes for leaders themselves, in line with similar singlelevel findings (e.g., Harms, 2011).

One possible explanation for these unexpected results can be traced in followers' shared cultural orientations and the related implicit leadership schemas. A closer examination of culturelevel norms in emotion expression suggests that in interdependent cultures people typically suppress the expression of emotional displays, especially those emotional displays that may threaten interpersonal harmony (e.g., antagonistic emotions, Markus and Kitayama, 1991; Biehl et al., 1997). Compared with independent cultures where the pursuit of positive emotions is typically promoted, norms of suppression are dominant in interdependent cultures, such as Greece (Matsumoto et al., 2008). Such norms are particularly influential in the experience and perception of emotion in social interaction. Compared with social interactions in independent cultures (e.g., UK, Germany), participants reported weaker positive emotions, stronger negative emotions, and lower felt understanding in social interactions in Greece, a collectivistic culture (Kafetsios and Nezlek, 2012; Kafetsios et al., 2018). Similar results were found in within-culture research for individuals with a more interdependent self-construal (Oishi et al., 2013).

Therefore, the present study directly tested this conjuncture following a within-culture approach. We assessed subordinates' self-construal and related it to leaders' avoidant attachment orientation. Self-construal refers to an individual's tendency to understand the self as connected with others, especially close others (interdependent), or distinct from others (independent, Cross et al., 2011). Typically, Western cultures nurture an independent self-construal emphasizing individual needs and personal autonomy. In turn, collectivistic cultures nurture an interdependent self-construal emphasizing interpersonal obligations, particularly obligations to in-group members, and relationships with others in general. Importantly, self-construal can vary not only between cultures but also within a single culture, and even within a given individual depending on the situation or the social context they are in Miyamoto and Wilken (2010). Hence, the consequences of interdependence on emotion are not limited to chronic effects of culture but can also be prominent in cases when individuals are primed with the respective self-construal. A critical assumption in that respect is that individuals with a 
different oriented self-construal also express and experience emotion differently, particularly within the context of their social relationships (Kafetsios et al., 2018; Kafetsios, in press), that can also include work relationships.

The present study considered leaders' attachment orientation as a proxy of emotion capabilities. Attachment orientations in adulthood result from early socialization experiences. A dominant avoidant attachment orientation is the result of experience of unresponsive parenting and feelings of insecurity. Avoidant individuals develop a negative view of others and distance themselves more from others and focus on the self (Fletcher et al., 2000). They suppress negative memories to protect themselves from emotional harm (Rom and Mikulincer, 2003), avoid affection and intimacy (Geller and Bamberger, 2009), oftentimes distancing themselves from social situations (Edelstein, 2006). This is done as a defense mechanism. On the other hand, anxious individuals have a strong need for intimacy and emotional closeness with others, however, consistently fear abandonment and loneliness and generally worry about their relationship to others (Popper and Amit, 2009). In order to overcome this fear, they engage in hyperactivating behavior, increasingly seeking close proximity to their attachment figure at all times (Mikulincer and Shaver, 2007; Richards and Schat, 2011). They rely strongly on others for help and support, and seek dependable leaders (Hansbrough, 2012).

The present paper elaborates on the cultural conditions that exist in collectivistic countries, which can help explain the link between followers' cultural identity and leaders' emotion suppression traits. We consider followers' culturally determined self-construal as an important moderator of leader-follower processes. Hence, due to followers' culturally determined perceptions, followers with a more interdependent self-construal orientation would be more positively affected by leaders who retain more suppression traits, especially avoidant attachment. Attachment avoidance is associated with a higher degree of emotion suppression (Gross and John, 2003), also at the work place (surface acting, Richards and Hackett, 2012; Richards and Schat, 2011) and is therefore a likely proxy for an emotion suppression trait. Following this rationale, we hypothesized (H1) that due to followers' culturally informed schemas, followers with more interdependent self-construal orientation would be more positively affected by leaders who retain more emotion suppression traits, especially avoidant attachment.

However, one could also entrain an alternative hypothesis. Followers' independence, and not interdependence, may be positively associated with leaders' avoidance orientation. Avoidant persons tend to perceive others as different from themselves as a result of defensive regulation that favors distancing the self from others and focusing on the self (Mikulincer, 1998) causing them to become self-reliant (Edelstein, 2006) and avoiding intimacy (Geller and Bamberger, 2009). According to Richards and Schat (2011) "followers high in attachment avoidance will behave in ways aimed at verifying their self-concept of a socially distant 'lone wolf"' (p. 689). Since avoidant individuals are likely to be self-reliant (Popper and Amit, 2009), they are likely to prefer similar self-reliance traits in leaders as well (Gruda, 2017). Therefore, one could expect that followers' independence would be associated with leaders' avoidant attachment if it is viewed from a dyadic perspective. If, however, this is not found, but instead followers' interdependence cultural orientation is linked with high leader avoidance, this would support our main hypothesis, which focuses on followers' culturally shaped implicit schemas regarding leaders' emotion suppression traits.

As in previous research, we tested these expectations with regard to a number of indicators revolving around emotion reactions at work. In addition to job satisfaction (Sŷ et al., 2006), positive and negative affect at work, and group cohesion perception (Kafetsios et al., 2012), we tested emotion labor, since emotion labor has been indicated as an important outcome of leadership processes (Ashkanasy and Humphrey, 2011) and also related to attachment orientations at work (Richards and Hackett, 2012). Finally, we considered loneliness as an indicator of personal well-being.

\section{MATERIALS AND METHODS}

\section{Sample}

Data were collected from 50 school directors (54\% males, average age $=50.67, \mathrm{SD}=3.79)$ and 250 of their subordinates $(39 \%$ males, average age was 41.37 years, $\mathrm{SD}=8.60$ ) with four subordinates nested within each director. The study was approved by the ethics committee at Psychology Department, the University of Crete. We invited directors and subordinates independently to participate in a study of "Emotional experience at work." None of those approached declined to participate and no monetary incentive was offered. Participants were informed in written about the general procedure of the study and that anonymity was guaranteed. After providing informed consent by virtue of questionnaire completion, ${ }^{1}$ participants completed the following previously used and translated versions of scales. Supervisors and subordinates completed the same questionnaire.

\section{Adult Attachment Orientations}

Chronic attachment orientation was assessed with the Greek version (Tsagarakis et al., 2007) of the Experiences in Close Relationships Questionnaire revised version (ECR-R; Fraley et al., 2000). Since this scale measures attachment as a two-dimensional continuous variable, attachment security corresponds to low scores on each, avoidance and anxiety, attachment dimension.

\section{Self-construal}

Chronic self-construal was measured with the Greek version (Kafetsios and Hess, 2013) of the Self-Construal Scale (SCS; Singelis, 1994). The SCS is comprised of 30-items using a 7-point scale $(1=$ strongly disagree, $7=$ strongly agree), measuring the strength of individuals' interdependent and independent self-construals. The independent self-construal relates to an emphasis on feeling separate and unique, while the interdependent self-construal subscale relates to an emphasis on feelings of connectedness and relations to others.

${ }^{1}$ Following information about the aims of the study, right to withdraw at any point, and anonymity, the first page of the survey stated that completion of the questionnaire constituted proof of participants' informed consent to take part in the study. 


\section{Emotion Labor Scale}

To assess surface acting (SA) and deep acting (DA), we used the scale provided by Diefendorff et al. (2005). The scale consists of six items, measured on a scale of 1 ("rarely or never") to 5 ("always or almost always"). Example items for SA include "I show feelings to customers that are different than what I feel inside" as well as "I put on a show or performance when interacting with customers," while example items for DA include "I try to actually experience the emotions that I must show to customers."

\section{Job Satisfaction}

This variable was assessed using 12 items from the Greek version of the General Index of Job Satisfaction (Brayfield and Rothe, 1951). The scale includes items such as "I am generally satisfied with my current job" and "I consider my job rather unpleasant."

\section{Positive and Negative Affect at Work}

Positive and negative affect (PA, NA) was measured with the Job Affect Scale (JAS; Brief et al., 1988). The full scale consists of 20 emotion adjectives describing participants' positive and negative affects at the workplace during the previous week. Items are reported on a 5-point Likert-type scale ranging from 1 (not at all) to 5 (very much). However, in this study we include merely 17 of these adjectives: nine positive (JAS-Positive Affectivity: active, excited, enthusiastic, calm, happy, energetic, relaxed, at rest, strong) and eight negative (JAS-Negative Affectivity: distressed, fearful, sad, scornful, hostile, nervous, sleepy, jittery).

\section{Perceived Cohesion}

We measured group cohesion using an adaptation in Greek of the Perceived Cohesion Scale (Bollen and Hoyle, 1990; Chin et al., 1999). The scale measures how a person evaluates how close s/he is to his/her group on a 7-point scale and participants completed this with reference to the team of school educators as a whole. It has six questions: for example, "I am satisfied that I am a member of this team"; "I feel that I belong to this group."

\section{Loneliness Perceptions}

We used the UCLA loneliness scale (Russel et al., 1980) that comprises 20 statements rated on a 4-point scale (1-not at all, 4 -very much) describing a thought or feeling around relationships. Example items are "I feel in tune with people around me," "I am no longer close to anyone."

\section{RESULTS}

Tables 1 and $\mathbf{2}$ present inter-correlations of all the study variables at both the subordinate and the supervisor level. A series of multilevel analyses were conducted in which subordinates' variables were treated as nested within groups, using the program HLM (Version 6.0; Raudenbush, 2004). There was one supervisor-follower group that was excluded from analyses due to data missing at the subordinate level resulting in 49 supervisor-level groups.

We first examined correlations between key study variables at each level: for directors and for subordinates separately. For directors tenure was not associated with any of the variables of interest and was hence dropped from the analyses. Women directors reported higher attachment anxiety $(\mathrm{M}=2.082, \mathrm{SD}=1.02)$ than male directors $[\mathrm{M}=2.34, \mathrm{SD}=0.59, F(1,49)=2.96, p<0.05]$. There were no other significant gender differences on the variables of interest. Main scale psychometric properties and correlations among study variables are presented in Table 1. As was expected (Kafetsios et al., 2014), supervisors' insecure attachment orientations were negatively related to positive work outcomes (job satisfaction, positive affect at work, perceived group cohesion) and were positively related to negative work outcomes (burnout, negative affect at work).

For subordinates, tenure was negatively associated with job satisfaction $[r(248)=-0.18, p<0.01]$, group cohesion $[r(248)=-0.26, p<0.001]$, and positive affect at work $[r(248)=-0.23, p<0.01]$. There were no significant gender differences apart from women reporting higher stress at work than men $[F(1,247)=9.96, p<0.01]$. Main scale psychometric properties and correlations among study variables are presented in Table 2. Higher independent and interdependent self-construals were both associated with higher positive work outcomes and lower negative work outcomes.

\section{Cross-Level Analyses of Directors' Attachment Orientations, and Work- Related Outcomes for Subordinates'}

We conducted a series of multilevel analyses. Since our data constituted a nested data structure, with subordinates-educators nested within supervisors-school director groups, and to provide a comprehensive examination, descriptive statistics of followers' measures were estimated by a series of unconditional models. By doing so, we were able to estimate the mean and variance within

TABLE 1 | Correlations among main study variables for directors.

\begin{tabular}{|c|c|c|c|c|c|c|c|c|c|}
\hline & $\mathbf{M}$ & SD & 1 & 2 & 3 & 4 & 5 & 6 & 7 \\
\hline 1. Avoidance & 2.59 & 0.72 & (0.80) & & & & & & \\
\hline 2. Anxiety & 2.56 & 0.85 & $0.50^{\star \star}$ & (0.86) & & & & & \\
\hline 3. Job satisfaction & 3.97 & 0.45 & $-0.30^{\star}$ & $-0.34^{*}$ & $(0.80)$ & & & & \\
\hline 4. Group cohesion & 6.15 & 0.79 & $-0.38^{\star \star}$ & $-0.46^{\star \star}$ & $0.43^{\star \star}$ & (0.92) & & & \\
\hline 5. PA at work & 3.35 & 0.65 & -0.22 & -0.15 & $0.62^{\star \star}$ & $0.34^{\star}$ & (0.85) & & \\
\hline 6. NA at work & 1.49 & 0.44 & $0.30^{*}$ & $0.35^{\star}$ & $-0.45^{\star \star}$ & $-0.43^{\star \star}$ & $-0.42^{\star \star}$ & $(0.75)$ & \\
\hline 7. Suppression & 2.56 & 0.75 & 0.23 & 0.22 & -0.26 & -0.08 & -0.28 & $0.38^{\star *}$ & $(0.79)$ \\
\hline
\end{tabular}

$N=49$. Cronbach alpha is reported in parentheses on the diagonal.

${ }^{*} p<.05,{ }^{* *} p<.01,{ }^{* *} p<.001$. 
TABLE 2 | Correlations among study variables for subordinates.

\begin{tabular}{|c|c|c|c|c|c|c|c|c|c|c|}
\hline & $\mathbf{M}$ & SD & 1 & 2 & 3 & 4 & 5 & 6 & 7 & 8 \\
\hline 1. Interdependent & 4.81 & 0.72 & (0.63) & & & & & & & \\
\hline 2. Independent & 4.61 & 0.57 & $0.37^{\star \star}$ & $(0.61)$ & & & & & & \\
\hline 3. Job satisfaction & 3.88 & 0.58 & $0.30^{\star \star}$ & $0.30^{\star \star}$ & $(0.87)$ & & & & & \\
\hline 4. Lonely & 1.84 & 0.42 & $-0.28^{\star \star}$ & $-0.33^{\star \star \star}$ & $-0.40^{\star \star \star}$ & $(0.87)$ & & & & \\
\hline 5. Group cohesion & 5.40 & 1.31 & $0.21^{\star \star}$ & $0.18^{\star \star}$ & $0.53^{\star \star}$ & $-0.51^{\star \star}$ & $(0.94)$ & & & \\
\hline 6. PA at work & 3.40 & 0.72 & $0.23^{\star \star}$ & $0.26^{\star \star \star}$ & $0.53^{\star \star \star}$ & $-0.32^{\star \star}$ & $0.40^{\star \star}$ & (0.86) & & \\
\hline 7. NA at work & 1.50 & 0.45 & $-0.21^{\star \star \star}$ & -0.06 & $-0.46^{\star \star \star}$ & $0.37^{\star \star \star}$ & $-0.38^{\star \star}$ & $-0.45^{\star \star}$ & (0.79) & \\
\hline 8. Deep acting & 3.46 & 0.82 & $0.22^{\star \star}$ & $0.26^{\star \star}$ & $0.26^{\star \star}$ & $-0.17^{\star \star}$ & $0.237^{\star \star}$ & $0.40^{\star \star}$ & $-0.23^{\star \star}$ & $(0.76)$ \\
\hline
\end{tabular}

$N=242-248$. Cronbach alpha is reported in parentheses on the diagonal.

${ }^{*} p<.05,{ }^{* *} p<.01,{ }^{* * *} p<.001$.

and between groups. The results of these analyses are summarized as follows (see Table 3):

$$
\begin{aligned}
& \text { Level } 1: y_{i j}=\beta_{0 j}+r_{i j}, \\
& \text { Level } 2: \beta_{0 j}=\gamma_{00}+u_{0 j} .
\end{aligned}
$$

We tested our hypothesis (H1) with a series of multilevel models, with which we assessed group-level differences in the mean of several work outcomes (job satisfaction, positive and negative affects at work, group cohesion, DA).

The main set of analyses examined relationships between leaders' avoidant and anxious attachment orientation and followers' job satisfaction, negative affect at work, group cohesion, loneliness, and DA. These analyses had subordinates' chronic independence and interdependence as predictors at level-1 (the follower level) group centered as follows (see Table 4):

$$
\begin{aligned}
& \left.\left.y_{i j}=\beta_{0 j}+\beta_{1 j} \text { (Independence }\right)+\beta_{2 j} \text { (Interdependence }\right)+r_{i j} \\
& \left.\beta_{0 j}=\gamma_{00}+\gamma_{01} \text { (Avoidance }\right)+\gamma_{02}(\text { Anxiety })+u_{0 j} \\
& \beta_{1 j}=\gamma_{10}+\gamma_{11}(\text { Avoidance })+\gamma_{12} \text { (Anxiety) }+u_{1 j} . \\
& \left.\beta_{2 j}=\gamma_{20}+\gamma_{21} \text { (Avoidance }\right)+\gamma_{22} \text { (Anxiety) }+u_{1 j} .
\end{aligned}
$$

Results indicated that supervisors' higher avoidance was related with educators' higher job satisfaction, group cohesion and DA, and lower negative affect and loneliness, for groups of subordinates with higher interdependence orientation. The lower half of Table 4 presented the level-1 relationships (slopes) of followers' two self-construal dimensions (independence and interdependence) with their own work outcomes by supervisors' attachment orientations. As indicated by the mean slope coefficient, followers' independent and interdependent self-construal was a significant predictor (level 1) of their job satisfaction, group cohesion, and DA, and negatively associated with loneliness and negative affect at work (especially interdependence). The remaining part of the lower panel of Table 3 shows the "interaction" between supervisors' avoidance and anxiety and followers' self-construal. This interaction was significant for supervisors' avoidant orientation. As is standard, we visualized interactions by calculating predicted values for observations (in our case individuals) at \pm 1 SD on interacting measures that interact. We find that for followers high on interdependent self-construal, high supervisor avoidance was associated with higher job satisfaction (predicted value $+1 \mathrm{SD}=0.44$ vs. $-1 \mathrm{SD}=-0.02$ ), group cohesion (predicted value $+1 \mathrm{SD}=1.02$ vs. $-1 \mathrm{SD}=0.10$ ), $\mathrm{DA}$ (predicted
TABLE 3 | Multilevel summary statistics (subordinate level).

\begin{tabular}{lccc}
\hline & Mean & $\begin{array}{c}\text { Within-group } \\
\text { variance }\end{array}$ & $\begin{array}{c}\text { Between-group } \\
\text { variance }\end{array}$ \\
\hline Job satisfaction & 3.87 & 0.31 & 0.04 \\
Positive affect & 3.38 & 0.43 & 0.08 \\
Negative affect & 1.49 & 0.44 & 0.12 \\
Group cohesion & 5.38 & 1.27 & 0.31 \\
Lonely & 1.84 & 0.17 & 0.01 \\
Deep acting & 3.45 & 0.78 & 0.27
\end{tabular}

value $+1 \mathrm{SD}=0.52$ vs. $-1 \mathrm{SD}=-0.18)$, and lower negative affect at work (predicted value $+1 \mathrm{SD}=-0.27$ vs. $-1 \mathrm{SD}=0.03$ ) as well as lower loneliness (predicted value $+1 \mathrm{SD}=-0.33$ vs. -1 $\mathrm{SD}=0.07)$

In a second step, we entered supervisors' SA in order to test whether/how this emotion suppression facet (Troth et al., in press) would influence the moderating effect of leaders' avoidant attachment in relationships between subordinates' avoidance and work outcomes. In two cases, supervisor SA reduced the moderating effect of avoidance on subordinates' job satisfaction and negative affect. There was also an interaction between supervisors' SA and followers' interdependence, i.e., higher SA was associated with higher job satisfaction and lower negative affect at work for groups of followers with higher interdependent self-construal (job satisfaction predicted value $+1 \mathrm{SD}=0.46$ vs. $-1 \mathrm{SD}=-0.08$, NA predicted value $+1 \mathrm{SD}=-0.22$ vs. -1 $\mathrm{SD}=-0.04)$.

\section{DISCUSSION}

The present study examined how followers' cultural identity, interdependent self-construal in particular, may affect work outcomes in relation to leaders' emotion suppression traits, answering recent research calls on this topic (Epitropaki et al., 2017). On the basis of previous findings on leader-follower interaction in Greece (Kafetsios et al., 2011, 2012, 2014), and also insights into the function of emotion suppression in social interaction in a collectivistic culture (Kafetsios et al., 2018), we expected that followers' interdependence would have more beneficial emotion and attitudinal outcomes for leaders higher on suppression traits.

As expected, leaders' avoidant attachment was, indeed, associated with followers' positive work attitudes (higher job satisfaction, 
TABLE 4 | Relationships between supervisors' avoidant attachment and subordinate outcomes as a function of subordinates' independent and interdependent self-construals.

\begin{tabular}{|c|c|c|c|c|c|c|c|c|c|c|}
\hline & \multicolumn{2}{|c|}{ Job satisfaction } & \multicolumn{2}{|c|}{ Negative affect } & \multicolumn{2}{|c|}{ Group cohesion } & \multicolumn{2}{|c|}{ Lonely } & \multicolumn{2}{|c|}{ Deep acting } \\
\hline & Step 1 & Step 2 & Step 1 & Step 2 & Step 1 & Step 2 & Step 1 & Step 2 & Step 1 & Step 2 \\
\hline Intercept, $\gamma_{00}$ & $\begin{array}{c}3.87^{\star \star \star} \\
(0.04)\end{array}$ & $\begin{array}{c}3.87^{\star \star \star} \\
(0.04)\end{array}$ & $\begin{array}{c}1.50^{\star \star \star} \\
(0.09)\end{array}$ & $\begin{array}{c}1.49^{\star \star \star} \\
(0.03)\end{array}$ & $\begin{array}{c}5.39^{\star \star \star} \\
(0.09)\end{array}$ & $\begin{array}{c}5.38^{\star \star \star} \\
(0.09)\end{array}$ & $\begin{array}{c}1.93^{\star \star \star} \\
(0.08)\end{array}$ & $\begin{array}{c}1.84^{\star \star \star} \\
(0.03)\end{array}$ & $\begin{array}{c}3.56^{\star \star \star} \\
(0.18)\end{array}$ & $\begin{array}{c}3.45^{\text {} \star \star \star} \\
(0.06)\end{array}$ \\
\hline Avoidance, $\gamma_{01}$ & $\begin{array}{c}-0.08 \\
(0.06)\end{array}$ & $\begin{array}{c}-0.08 \\
(0.06)\end{array}$ & $\begin{array}{c}0.19^{\star \star \star} \\
(0.05)\end{array}$ & $\begin{array}{l}0.18^{\star *} \\
(0.05)\end{array}$ & $\begin{array}{l}-0.12 \\
(0.16)\end{array}$ & $\begin{array}{c}-0.12 \\
(0.16)\end{array}$ & $\begin{array}{c}0.04 \\
(0.04)\end{array}$ & $\begin{array}{c}0.04 \\
(0.04)\end{array}$ & $\begin{array}{l}-0.15 \\
(0.09)\end{array}$ & $\begin{array}{r}-0.14 \\
(0.09)\end{array}$ \\
\hline Anxiety, $\gamma_{02}$ & $\begin{array}{l}-0.12 \\
(0.07)\end{array}$ & $\begin{array}{l}-0.12 \\
(0.07)\end{array}$ & $\begin{array}{l}-0.05 \\
(0.04)\end{array}$ & $\begin{array}{l}-0.04 \\
(0.04)\end{array}$ & $\begin{array}{c}-0.16 \\
(0.15)\end{array}$ & $\begin{array}{c}-0.16 \\
(0.15)\end{array}$ & $\begin{array}{l}0.001 \\
(0.04)\end{array}$ & $\begin{array}{l}0.007 \\
(0.04)\end{array}$ & $\begin{array}{c}0.06 \\
(0.10)\end{array}$ & \\
\hline \multicolumn{11}{|c|}{ Subordinates' independence slope } \\
\hline Mean slope, $\gamma_{10}$ & $\begin{array}{l}0.18^{\star \star} \\
(0.07)\end{array}$ & $\begin{array}{l}0.15^{\star} \\
(0.07)\end{array}$ & $\begin{array}{r}-0.05 \\
(0.06)\end{array}$ & $\begin{array}{l}-0.04 \\
(0.06)\end{array}$ & $\begin{array}{c}0.20 \\
(0.13)\end{array}$ & $\begin{array}{c}0.19 \\
(0.14)\end{array}$ & $\begin{array}{c}-0.17^{\star \star} \\
(0.05)\end{array}$ & $\begin{array}{c}-0.15^{\star \star} \\
(0.05)\end{array}$ & $\begin{array}{l}0.27^{\star} \\
(0.12)\end{array}$ & $\begin{array}{l}0.25^{\star} \\
(0.13)\end{array}$ \\
\hline Avoidance, $\gamma_{11}$ & $\begin{array}{l}-0.12 \\
(0.13)\end{array}$ & $\begin{array}{l}-0.09 \\
(0.13)\end{array}$ & $\begin{array}{c}-0.06 \\
(0.12)\end{array}$ & $\begin{array}{l}-0.05 \\
(0.13)\end{array}$ & $\begin{array}{c}-0.26 \\
(0.21)\end{array}$ & $\begin{array}{c}-0.26 \\
(0.21)\end{array}$ & $\begin{array}{l}0.17^{*} \\
(0.09)\end{array}$ & $\begin{array}{l}0.18^{\star} \\
(0.09)\end{array}$ & $\begin{array}{c}-0.33 \\
(0.21)\end{array}$ & $\begin{array}{c}-0.26 \\
(0.22)\end{array}$ \\
\hline Anxiety, $\gamma_{12}$ & $\begin{array}{r}-0.12 \\
(0.10)\end{array}$ & $\begin{array}{l}-0.14 \\
(0.10)\end{array}$ & $\begin{array}{r}-0.06 \\
(0.09)\end{array}$ & $\begin{array}{l}-0.07 \\
(0.09)\end{array}$ & $\begin{array}{l}-0.04 \\
(0.09)\end{array}$ & $\begin{array}{r}-0.04 \\
(0.09)\end{array}$ & $\begin{array}{c}0.04 \\
(0.05)\end{array}$ & $\begin{array}{c}0.03 \\
(0.06)\end{array}$ & $\begin{array}{c}0.07 \\
(0.11)\end{array}$ & $\begin{array}{c}0.07 \\
(0.13)\end{array}$ \\
\hline \multicolumn{11}{|c|}{ Subordinates' interdependence slope } \\
\hline Mean slope, $\gamma_{20}$ & $\begin{array}{l}0.21^{\star *} \\
(0.06)\end{array}$ & $\begin{array}{l}0.19^{\star \star} \\
(0.05)\end{array}$ & $\begin{array}{c}-0.12^{*} \\
(0.05)\end{array}$ & $\begin{array}{c}-0.13^{*} \\
(0.05)\end{array}$ & $\begin{array}{c}0.56^{\star \star \star} \\
(0.14)\end{array}$ & $\begin{array}{c}0.56^{\star \star \star} \\
(0.14)\end{array}$ & $\begin{array}{c}-0.13^{\star *} \\
(0.04)\end{array}$ & $\begin{array}{c}-0.12^{*} \\
(0.04)\end{array}$ & $\begin{array}{l}0.17^{*} \\
(0.09)\end{array}$ & $\begin{array}{l}0.17^{\star} \\
(0.06)\end{array}$ \\
\hline Avoidance, $\gamma_{21}$ & $\begin{array}{l}0.23^{*} \\
(0.10)\end{array}$ & $\begin{array}{c}0.13 \\
(0.11)\end{array}$ & $\begin{array}{c}-0.15^{\star} \\
(0.07)\end{array}$ & $\begin{array}{l}-0.09 \\
(0.05)\end{array}$ & $\begin{array}{l}0.46^{\star} \\
(0.23)\end{array}$ & $\begin{array}{c}0.45^{\wedge} \\
(0.24)\end{array}$ & $\begin{array}{c}-0.20^{* *} \\
(0.06)\end{array}$ & $\begin{array}{c}-0.17^{\star} \\
(0.07)\end{array}$ & $\begin{array}{l}0.35^{\star \star} \\
(0.11)\end{array}$ & $\begin{array}{l}0.26^{*} \\
(0.13)\end{array}$ \\
\hline Anxiety, $\gamma_{22}$ & $\begin{array}{c}-0.04 \\
(0.06)\end{array}$ & $\begin{array}{l}-0.05 \\
(0.08)\end{array}$ & $\begin{array}{c}0.06 \\
(0.05)\end{array}$ & $\begin{array}{c}0.06 \\
(0.05)\end{array}$ & $\begin{array}{c}-0.40^{\star} \\
(0.16)\end{array}$ & $\begin{array}{c}-0.40^{\star} \\
(0.16)\end{array}$ & $\begin{array}{l}-0.02 \\
(0.03)\end{array}$ & $\begin{array}{l}-0.03 \\
(0.02)\end{array}$ & $\begin{array}{l}-0.06 \\
(0.06)\end{array}$ & $\begin{array}{r}-0.06 \\
(0.09)\end{array}$ \\
\hline Surface, $\gamma_{23}$ & & $\begin{array}{c}0.27^{\star \star \star} \\
(0.06)\end{array}$ & & $\begin{array}{c}-0.09^{\wedge} \\
(0.05)\end{array}$ & & $\begin{array}{l}0.004 \\
(0.18)\end{array}$ & & $\begin{array}{l}-0.09 \\
(0.06)\end{array}$ & & $\begin{array}{l}0.26^{\wedge} \\
(0.13)\end{array}$ \\
\hline
\end{tabular}

Coefficients in bold are discussed in the results section.

${ }^{*} p<.05,{ }^{* *} p<.01,{ }^{* * *} p<.001$.

group cohesion perceptions, and DA) and less-negative emotion at work and loneliness feelings for groups of followers higher on interdependent self-construal. As a further attestation to our central expectation, leaders' SA rendered the moderating effect of leaders' avoidant attachment non-significant in several cases and was a significant moderator in two cases for followers with higher interdependent self-construal. These results can be explained with recourse to central leadership theories. Leadership categorization theories (e.g., Lord et al., 1984) maintain that specific leader personality traits are inherent of followers' implicit leadership theories (ILTs; Shondrick et al., 2010) as well as group-based perceptions. Followers with a higher interdependent cultural orientation in Greece follow culture-level prescriptive norms of higher suppression (Matsumoto et al., 2008) and hence recognize those leaders as more leader prototypical.

This is a unique finding that is also suggestive of the likely processes at play, and the level of analysis involved. If results were viewed from a dyadic perspective, one may expect that interdependent followers would not "match" with avoidant leaders. Recent experimental and correlational studies (in France, USA, and Greece) attest that avoidant followers "match" with more independent leaders (Gruda and Kafetsios, 2017). However, the reverse relationship (i.e., independent followers matching with avoidant leaders) was not observed.

Our research is not without limitations. Given that our study is correlational, results concerning cross-level relationships could also be describing a reverse causal relationship between leader attachment orientation and subordinates' self-construal and work outcomes. Moreover, one cannot know, based on this study, whether it was dyadic or group-level processes, involved. Further research could disentangle the possible dynamics of group-level norms and dyadic-level relationships, which may function simultaneously in leader-follower exchanges. Finally, the study took place in a public organization in Greece, which may have further exacerbated likely cultural orientation effects. Further research is needed in order to clarify the influence of emotion-related cultural norms in different cultures and organizations.

\section{Implications}

The obvious practical implication of the current findings is that cultural identity and, therefore, the cultural (and organizational) context can shape followers' perceptions regarding specific emotion-related traits. As we have shown, culture can influence how followers perceive their leaders. Going beyond the moderating effect, culture can further even change traditionally held assumptions of attachment orientation "matching" between individuals, such as leaders and followers. If subordinates with an interdependent attachment orientation, report higher job satisfaction when they are assigned to a highly avoidant and emotion-suppressing leaders, previous beliefs about the strength of attachment schemas need to be revisited through a cultural lens. The overarching role of culture should not be ignored.

In terms of practical implications, organizations, and in particular management, needs to be aware of the influencing role of culture. Since attachment orientations are easily measured and reveal the importance of self- and others-schemas as well 
organizations might be inclined to use these tools during talent recruitment or in determining the right group of subordinates and leaders to handle a specific project or task. Although being aware that subordinates might hold different relationship expectations and preferences when it comes to their leader, managers should be very careful not to simply assign subordinates to "matching" leaders, in terms of attachment styles. This is particularly important for organizations with international teams or those expanding abroad. It might just be that interdependent followers indeed prefer an independent leader, since they are seen as more masculine or even capable (Kafetsios et al., 2014). That is because followers' cultural orientation also influences their leader preference, as we have shown in this paper.

\section{CONCLUSION}

This study adds to a stream of research that highlights the interplay between cultural norms and cultural identity at the individual level with attachment orientations in organizational contexts (e.g., Gruda and Kafetsios, 2017). With few exceptions (e.g., Rothbaum et al., 2000), the interplay between attachment orientations and

\section{REFERENCES}

Antonakis, J., Ashkanasy, N. M., and Dasborough, M. T. (2009). Does leadership need emotional intelligence? Leadersh. Q. 20, 247-261. doi:10.1016/j. leaqua.2009.01.006

Antonakis, J., Day, D. V., and Schyns, B. (2012). Leadership and individual differences: at the cusp of a renaissance. Leadersh. Q. 23, 643-650. doi:10.1016/j. leaqua.2012.05.002

Ashkanasy, N. M., Härtel, C. E., and Daus, C. S. (2002). Diversity and emotion: the new frontiers in organizational behavior research. J. Manage. 28, 307-338. doi:10.1177/014920630202800304

Ashkanasy, N. M., and Humphrey, R. H. (2011). "A multi-level view of leadership and emotions: leading with emotional labor," in The Sage Handbook of Leadership, eds A. Bryman, D. Collinson, K. Grint, B. Jackson, and M. Uhl-Bien (London, UK: SAGE), 363-377.

Biehl, M., Matsumoto, D., Ekman, P., Hearn, V., Heider, K., Kudoh, T., et al. (1997). Matsumoto and Ekman's Japanese and Caucasian Facial Expressions of Emotion (JACFEE): reliability data and cross-national differences. J. Nonverbal Behav. 21, 3-21. doi:10.1023/A:1024902500935

Bollen, K. A., and Hoyle, R. H. (1990). Perceived cohesion: a conceptual and empirical examination. Soc. Forces 69, 479-504. doi:10.2307/2579670

Bono, J. E., Ilies, R. (2006). Charisma, positive emotions and mood contagion. Leadersh. Q. 17, 317-334.

Bono, J. E., Foldes, H. J., Vinson, G., and Muros, J. P. (2007). Workplace emotions: the role of supervision and leadership. J. Appl. Psychol. 92, 1357. doi:10.1037/0021-9010.92.5.1357

Brayfield, A. H., and Rothe, H. F. (1951). An index of job satisfaction. J. Appl. Psychol. 35, 307. doi:10.1037/h0055617

Brief, A. P., Burke, M. J., George, J. M., Robinson, B. S., and Webster, J. (1988). Should negative affectivity remain an unmeasured variable in the study of job stress? J. Appl. Psychol. 73, 193. doi:10.1037/0021-9010.73.2.193

Butler, E. A., Lee, T. L., and Gross, J. J. (2007). Emotion regulation and culture: are the social consequences of emotion suppression culture-specific? Emotion 7, 30. doi:10.1037/1528-3542.7.1.30

Chin, W. W., Salisbury, W. D., Pearson, A. W., and Stollak, M. J. (1999). Perceived cohesion in small groups: adapting and testing the perceived cohesion scale in a smallgroup setting. Small Group Res. 30, 751-766. doi:10.1177/104649649903000605

Cross, S. E., Hardin, E. E., and Gercek-Swing, B. (2011). The what, how, why, and where of self-construal. Person. Soc. Psychol. Rev. 15, 142-179. doi: $10.1177 / 1088868310373752$ culture has been more rarely examined. Moreover, the study provides a further attestation to the different functions emotion propensities have at different levels of analysis.

\section{ETHICS STATEMENT}

This study was carried out in accordance with the recommendations of the ethics committee at the Psychology Department, University of Crete.

\section{AUTHOR CONTRIBUTIONS}

KK conducted the study, analyzed the data, and drafted the manuscript. DG contributed to writing the manuscript and to the analyses.

\section{ACKNOWLEDGMENTS}

We would like to thank Mrs P. Mataftsi and Mrs Z. Tsoutsiou for valuable assistance with data collection.

Diefendorff, J. M., Croyle, M. H., and Gosserand, R. H. (2005). The dimensionality and antecedents of emotional labor strategies. J. Vocat. Behav. 66, 339-357. doi:10.1016/j.jvb.2004.02.001

Edelstein, R. S. (2006). Attachment and emotional memory: investigating the source and extent of avoidant memory impairments. Emotion 6, 340 doi:10.1037/1528-3542.6.2.340

Epitropaki, O., Kark, R., Mainemelis, C., and Lord, R. G. (2017). Leadership and followership identity processes: a multilevel review. Leadersh. Q. 28, 104-129. doi:10.1016/j.leaqua.2016.10.003

Fisk, G. M., Friesen, J. P. (2012). Perceptions of leader emotion regulation and LMX as predictors of followers' job satisfaction and organizational citizenship behaviors. Leadersh. Q. 23, 1-12.

Fletcher, G. J., Simpson, J. A., and Thomas, G. (2000). Ideals, perceptions, and evaluations in early relationship development. J. Pers. Soc. Psychol. 79, 933. doi:10.1037/0022-3514.79.6.933

Fraley, R. C., Waller, N. G., and Brennan, K. A. (2000). An item response theory analysis of self-report measures of adult attachment. J. Pers. Soc. Psychol. 78, 350. doi:10.1037/0022-3514.78.2.350

Geller, D., and Bamberger, P. (2009). Bringing avoidance and anxiety to the job: attachment style and instrumental helping behavior among co-workers. Hum. Relations 62, 1803-1827. doi:10.1177/0018726709337524

Gross, J. J., and John, O. P. (2003). Individual differences in two emotion regulation processes: implications for affect, relationships, and well-being. J. Pers. Soc. Psychol. 85, 348. doi:10.1037/0022-3514.85.2.348

Gruda, D. (2017). "I know a leader when I see one: implicit leadership theories and attachment styles," in Academy of Management Proceedings, Vol. 2017 (Academy of Management), 16225.

Gruda, D., and Kafetsios, K. (2017). "A case of mistaken identity: impact of attachment on leader transference," in Paper Presented at the Interdisciplinary Perspectives on Leadership Symposium (Mykonos, Greece).

Hansbrough, T. K. (2012). The construction of a transformational leader: follower attachment and leadership perceptions. J. Appl. Soc. Psychol. 42, 1533-1549. doi:10.1111/j.1559-1816.2012.00913.x

Harms, P. D. (2011). Adult attachment styles in the workplace. Hum. Res. Manage. Rev. 21, 285-296. doi:10.1016/j.hrmr.2010.10.006

Hofstede, G. (2001). Culture's Consequences: Comparing Values, Behaviors, Institutions, and Organizations across Cultures. Thousand Oaks, CA: SAGE.

Humphrey, R. H. (2002). The many faces of emotional leadership. Leadersh. Q. 13, 493-504. doi:10.1016/S1048-9843(02)00140-6 
Kafetsios, K. (in press). "Spouses' independent and interdependent self-construal and well-being: a dyadic analysis," in Close Relationships and Happiness across Cultures, eds N. Sumer and M. Demir (Springer).

Kafetsios, K., Athanasiadou, M., and Dimou, N. (2014). Leaders' and subordinates' attachment orientations, emotion regulation capabilities and affect at work: a multilevel analysis. Leadersh. Q. 25, 512-527. doi:10.1016/j. leaqua.2013.11.010

Kafetsios, K., and Hess, U. (2013). Effects of activated and dispositional self-construal on emotion decoding accuracy. J. Nonverbal Behav. 37, 191-205. doi:10.1007/s10919-013-0149-x

Kafetsios, K., Hess, U., and Nezlek, J. B. (2018). Self-construal, affective valence of the encounter, and quality of social interactions: within and cross-culture examination. J. Soc. Psychol. 158, 82-92. doi:10.1080/00224545.2017. 1305326

Kafetsios, K., and Nezlek, J. B. (2012). Emotion and support perceptions in everyday social interaction: testing the "less is more" hypothesis in two cultures. J. Soc. Pers. Relat. 29, 165-184. doi:10.1177/0265407511420194

Kafetsios, K., Nezlek, J. B., and Vassilakou, T. (2012). Relationships between leaders' and subordinates' emotion regulation and satisfaction and affect at work. J. Soc. Psychol. 152, 436-457. doi:10.1080/00224545.2011.632788

Kafetsios, K., Nezlek, J. B., and Vassiou, A. (2011). A multilevel analysis of relationships between leaders' and subordinates' emotional intelligence and emotional outcomes. J. Appl. Soc. Psychol. 41, 1121-1144. doi:10.1111/j.15591816.2011.00750.x

Lord, R. G., Foti, R. J., and De Vader, C. L. (1984). A test of leadership categorization theory: internal structure, information processing, and leadership perceptions. Organ. Behav. Hum. Perform. 34, 343-378. doi:10.1016/0030-5073(84)90043-6

Markus, H. R., and Kitayama, S. (1991). Culture and the self: implications for cognition, emotion, and motivation. Psychol. Rev. 98, 224. doi:10.1037/0033295X.98.2.224

Matsumoto, D., Yoo, S. H., and Nakagawa, S. (2008). Culture, emotion regulation, and adjustment. J. Pers. Soc. Psychol. 94, 925. doi:10.1037/0022-3514. 94.6 .925

McColl-Kennedy, J. R., and Anderson, R. D. (2002). Impact of leadership style and emotions on subordinate performance. Leadersh. Q. 13, 545-559. doi:10.1016/ S1048-9843(02)00143-1

Mikulincer, M. (1998). Adult attachment style and individual differences in functional versus dysfunctional experiences of anger. J. Pers. Soc. Psychol. 74, 513. doi:10.1037/0022-3514.74.2.513

Mikulincer, M., and Shaver, P. R. (2007). Boosting attachment security to promote mental health, prosocial values, and inter-group tolerance. Psychol. Inq. 18, 139-156. doi:10.1080/10478400701512646

Miyamoto, Y., and Wilken, B. (2010). Culturally contingent situated cognition: influencing other people fosters analytic perception in the United States but not in Japan. Psychol. Sci. 21, 1616-1622. doi:10.1177/0956797610385954

Newcombe, M. J., and Ashkanasy, N. M. (2002). The role of affect and affective congruence in perceptions of leaders: an experimental study. Leadersh. Q. 13, 601-614. doi:10.1016/S1048-9843(02)00146-7

Oishi, S., Akimoto, S. A., Richards, J. R. K., and Suh, E. M. (2013). Feeling understood as a key to cultural differences in life satisfaction. J. Res. Pers. 47, 488-491. doi:10.1016/j.jrp.2013.04.011

Pirola-Merlo, A., Härtel, C., Mann, L., and Hirst, G. (2002). How leaders influence the impact of affective events on team climate and performance in R\&D teams. Leadersh. Q. 13, 561-581. doi:10.1016/S1048-9843(02)00144-3

Popper, M., and Amit, K. (2009). Attachment and leader's development via experiences. Leadersh. Q. 20, 749-763. doi:10.1016/j.leaqua.2009.06.005

Raudenbush, S. W. (2004). HLM 6: Hierarchical Linear and Nonlinear Modeling. Newbury Park, CA: Scientific Software International.
Richards, D. A., and Hackett, R. D. (2012). Attachment and emotion regulation: compensatory interactions and leader-member exchange. Leadersh. Q. 23, 686-701. doi:10.1016/j.leaqua.2012.03.005

Richards, D. A., and Schat, A. C. (2011). Attachment at (not to) work: applying attachment theory to explain individual behavior in organizations. J. Appl. Psychol. 96, 169-182. doi:10.1037/a0020372

Riggio, R. E., and Lee, J. (2007). Emotional and interpersonal competencies and leader development. Hum. Res. Manage. Rev. 17, 418-426. doi:10.1016/j. hrmr.2007.08.008

Rom, E., and Mikulincer, M. (2003). Attachment theory and group processes: the association between attachment style and group-related representations, goals, memories, and functioning. J.Pers. Soc. Psychol. 84, 1220-1235. doi:10.1037/0022-3514.84.6.1220

Rothbaum, F., Weisz, J., Pott, M., Miyake, K., and Morelli, G. (2000). Attachment and culture: security in the United States and Japan. Am. Psychol. 55, 1093. doi:10.1037/0003-066X.55.10.1093

Russel, D., Peplau, L. A., and Cutrona, C. E. (1980). The revised UCLA Loneliness Scale: concurrent and discriminant validity evidence. J. Person. Soc. Psychol. 39, 472-480. doi:10.1037/0022-3514.39.3.472

Shondrick, S. J., Dinh, J. E., and Lord, R. G. (2010). Developments in implicit leadership theory and cognitive science: applications to improving measurement and understanding alternatives to hierarchical leadership. Leadersh. Q. 21, 959-978. doi:10.1016/j.leaqua.2010.10.004

Singelis, T.M. (1994). Themeasurement ofindependentandinterdependentself-construals. Pers. Soc. Psychol. Bull. 20, 580-591. doi:10.1177/0146167294205014

Sŷ, T., Tram, S., and O'Hara, L. A. (2006). Relation of employee and manager emotional intelligence to job satisfaction and performance. J. Vocat. Behav. 68 , 461-473. doi:10.1016/j.jvb.2005.10.003

Tackman, A. M., and Srivastava, S. (2016). Social responses to expressive suppression: the role of personality judgments. J. Pers. Soc. Psychol. 110, 574. doi:10.1037/pspp0000053

Troth, A. C., Lawrence, S. A., Jordan, P. J., and Ashkanasy, N. M. (in press). Interpersonal emotion regulation in the workplace: a conceptual and operational review and future research Agenda. Int. J. Manage. Rev. doi:10.1111/ ijmr.12144

Tsagarakis, M., Kafetsios, K., and Stalikas, A. (2007). Reliability and validity of the Greek version of the revised experiences in close relationships measure of adult attachment. Eur. J. Psychol. Assess. 23, 47-55. doi:10.1027/1015-5759.23.1.47

Van Kleef, G. A., Homan, A. C., Beersma, B., Van Knippenberg, D., Van Knippenberg, B., and Damen, F. (2009). Searing sentiment or cold calculation? The effects of leader emotional displays on team performance depend on follower epistemic motivation. Acad. Manage. J. 52, 562-580. doi:10.5465/AMJ.2009.41331253

Van Kleef, G. A., Homan, A. C., and Cheshin, A. (2012). Emotional influence at work: take it EASI. Organ. Psychol. Rev. 2, 311-339. doi:10.1177/2041386612454911

Wong, C. S., and Law, S. K. (2002). The effects of leader and follower emotional intelligence on performance and attitude: an exploratory study. Leadersh. Q. 13, 243-274. doi:10.1016/S1048-9843(02)00099-1

Conflict of Interest Statement: The authors declare that the research was conducted in the absence of any commercial or financial relationships that could be construed as a potential conflict of interest.

Copyright $\odot 2018$ Kafetsios and Gruda. This is an open-access article distributed under the terms of the Creative Commons Attribution License (CC BY). The use, distribution or reproduction in other forums is permitted, provided the original author(s) and the copyright owner are credited and that the original publication in this journal is cited, in accordance with accepted academic practice. No use, distribution or reproduction is permitted which does not comply with these terms. 